\title{
Influence of Gum Arabic from Acacia senegal var. kerensis on the Modifications of Pasting and Textural Properties of Cassava and Corn Starches
}

\author{
Virate Jepkogei Kiprop ${ }^{1,2^{*}}$, Mary N. Omwamba1, Symon M. Mahungu1 \\ ${ }^{1}$ Department of Dairy and Food Science and Technology, Egerton University, Egerton, Kenya \\ ${ }^{2}$ Department of Applied Sciences, The Eldoret National Polytechnic, Eldoret, Kenya \\ Email: *viokip2011@gmail.com
}

How to cite this paper: Kiprop, V.J., Omwamba, M.N. and Mahungu, S.M. (2021) Influence of Gum Arabic from Acacia senegal var. kerensis on the Modifications of Pasting and Textural Properties of Cassava and Corn Starches. Food and Nutrition Sciences, 12, 1098-1115.

https://doi.org/10.4236/fns.2021.1211081

Received: October 21, 2021

Accepted: November 23, 2021

Published: November 26, 2021

Copyright $\odot 2021$ by author(s) and Scientific Research Publishing Inc. This work is licensed under the Creative Commons Attribution International License (CC BY 4.0).

http://creativecommons.org/licenses/by/4.0/

\begin{abstract}
The use of hydrocolloids to modify the properties of native starches has been on the rise in the recent times due to the market demand for natural, safe and economical food ingredients. The objective of this study was to investigate the effect of gum Arabic from Acacia senegal var. kerensis to modify pasting and textural properties of corn and cassava starches, as an alternative to chemical and enzymatic modification. Blends were prepared by substituting the starches with gum at different levels $(0 \%, 0.5 \%, 2.0 \%, 4.0 \%, 6.0 \%$ and $8.0 \%)$, whereas native corn and cassava starches were used as control. The pasting properties of the starch-gum mixed systems were determined using the Brabender viscograph while the textural properties (firmness, consistency, cohesiveness and work of cohesion) were determined using Texture Analyzer. Results showed that the gum Arabic significantly decreased all the viscosity parameters (peak viscosity, final viscosity, break down and setback values) of both starches at all levels of substitution. However, there was no significant effect of gum Arabic on the pasting temperature $\left(72.05^{\circ} \mathrm{C}-71.85^{\circ} \mathrm{C}\right)$ for corn starch and $\left(68.90^{\circ} \mathrm{C}\right.$ $-68.65^{\circ} \mathrm{C}$ ) for cassava starch. The degree of gel firmness and consistency was higher in corn starch than in cassava starch and the effect of gum addition differed with each starch. The findings from this study indicate that gum Arabic significantly modified the pasting and textural properties of corn and cassava starches due to strong interaction between the gum and the starches. Hence, this property of gum Arabic could be useful in controlling starch retrogradation and determining starch end use functionality.
\end{abstract}

\section{Keywords}

Starch, Gum Arabic, Pasting Properties, Textural Properties, Retrogradation 


\section{Introduction}

Starch is the main source of energy in the human diet and the most abundant polysaccharides, mainly obtained from cereals and tubers. Starch is gaining biggest attention as compared to other carbohydrate polymers and the abundant production of starch has a bright future in sustainable food supply to the world [1]. Starches with industrial significance are from corn, potato, cassava, wheat and rice [2]. However, studies have indicated that native corn and cassava starches generally have limited functionality due to low shear stress resistance, susceptibility to thermal degradation, high retrogradation rate and syneresis. As a consequence, this has reduced corn and cassava starches applications in food systems and industries. Therefore, to improve the functionality of native starches, physical, chemical, enzymatic methods are used. However, due to market demand for economical, safe and natural food ingredients, different types of hydrocolloids are being extensively used to modify properties of different native starches such as pasting and texture [3].

Cereal grains contain $60 \%$ to $70 \%$ starch and an excellent source of energy, vitamin and minerals including fat soluble vitamin $\mathrm{E}$, which is an essential antioxidant [4]. Corn or maize (Zea mays) is one of the cereals of worldwide importance, the grain is used for human consumption and the starch has important industrial applications [5] while cassava (Manihot esculenta Crantz) is one of the tuber crops that has gained attention in developing world because of its economic importance in addressing food insecurity [6]. The advantage associated with cassava starch is that it is not only easily extracted using simple methods but also it is versatile in functionality as compared to starches from other sources due to its clear paste with a bland taste and relatively high viscosity and low cost [7]. Cassava starch has widespread usage in the food industry including bread, cakes, extruded cereals, beverages and sauces [8]. Corn starch contributes to $70 \%$ of the world starch requirements. It has extensively been used for syrup production especially high fructose corn syrup for industrial needs. Corn also produces high amylose starch; it has an elevated level of gelatinization temperature compared to other types of starch and maintains its resistant starch content during baking, mild extrusion and in further food processing techniques [2] [9].

Hydrocolloids are rich in hydrophilic groups that have good water binding ability thus modify the rheology of aqueous systems to which they are added [1]. Hydrocolloids (gums) are utilized in food industries since they improve stability, modify textural profile and reduce the retrogradation rate of the starch. The blending of starch and gums is crucial in improving the functionalities of starch and the quality of products without increasing caloric levels [10]. The mechanisms of hydrocolloid modification on pasting properties of starch have been explained to be influenced by 1) the network structure of molecules in the continuous phase 2) the characteristics of the hydrocolloid in the continuous phase 3 ) granule swelling in the starch-hydrocolloid system 4) interactions between swollen starch granule and granule fragments, interaction between the continuous 
phase and dispersion phase, any electrostatic interaction between starch granule and hydrocolloid molecules [11] [12].

Gum Arabic (GA) or acacia gum is obtained from various species of acacia tree and has been reported to be an encapsulating, emulsifying and thickening agent [13]. Gum Arabic consists mainly of high-molecular weight polysaccharides and their calcium, magnesium and potassium salts, which on hydrolysis, yield three main fractions of polysaccharides and proteins that is arabinogalac$\tan (\mathrm{AG})$, arabinogalactan protein (AGP) and glycoprotein (GP), which differ from their molecular weight and chemical composition. Among these fractions, AGP is the most interfacially active component and primarily responsible for the emulsifying properties of GA [14]. Acacia gum is widely used in the food industry mainly to impart desirable qualities because of its influence over viscosity, body and texture [15]. Studies have shown that starch-gum Arabic blends have the ability to retain flavor thus provides an opportunity to extend its application in edible/biodegradable film formation [1] [13]. However, the extend of modifications caused by gum Arabic from the Acacia senegal var. kerensis on rheological and textural properties of starches remains to be unknown.

Several recent studies have investigated starch-hydrocolloid combination aimed at overcoming the deficiencies of native and modified starches [16] [17]. The properties of native starch were changed to a certain degree by the addition of hydrocolloids/gums in all of these studies. The study of [8] found that addition of gum Arabic (GA) into a tapioca starch suspension showed a reduction in swelling power, solubility index and peak viscosity, which states that GA can be used as a stabilizer and viscosity controlling agent in the food industry. According to [16], low concentrations of GA can beneficially improve the rheological behavior of tapioca starch. Observation made by [13] depicted that mixing wheat or potato starch with Arabic gum did not have any significant effect on the viscosity and pasting properties of the starch-hydrocolloid blends. The recognition of pasting properties is a vital measure of the processing conditions of foods and their constituents. Such understanding enables a processor to optimize pressuretemperature-shear limits to attain a product of required uniformity [18]. Pasting and textural properties of starches are very important for food product development mainly for modifying texture and stability of the products.

The objective of this study was to examine the influence of gum Arabic from Acacia senegal var. kerensis on the pasting and textural properties of corn and cassava starches. The findings from this study supply scientific data for expanding the applied range of GA in food industries. Accordingly, a better understanding of the effects and interactions of this hydrocolloid on cassava and corn starches could be beneficial for its utilization to improve storage stability and textural quality of cassava and corn starch-based foods.

\section{Materials and Methods}

\subsection{Materials}

Native cassava/tapioca and corn starches were purchased from Ingredion Hold- 
ing LLC, Kenya. Gum Arabic from Acacia senegal var. kerensis was sourced from Kenya Forest Research Institute (KEFRI), Nairobi, Kenya.

\subsection{Sample Preparation}

Gum Arabic from Acacia senegal var. kerensis was prepared at Egerton University Food processing plant. The gum was sorted by removing dirt, remnants of the bark and any foreign matter prior to milling into fine particles and then stored in thermopak containers with proper sealing prior to the analyses. Formulations of starch-gum mixture were prepared to obtain slurries made up of $40 \mathrm{~g}$, gum Arabic was added at varying levels ( $0 \%, 0.5 \%, 2.0 \%, 4.0 \%, 6.0 \%$ and $8.0 \% \mathrm{~g} / \mathrm{g}$ on dry weight basis) by substituting the amount of starch. The samples were mixed thoroughly using a shaker to obtain a homogenous starch-gum mixture. Approximately $3 \mathrm{~g}$ of the starch-gum mixture and native corn and cassava starches were taken to verify for moisture content using rapid moisture meter at $105^{\circ} \mathrm{C}$. Once the moisture content of each sample was obtained, a correction was made to $14 \%$ and the exact amount of starch and water was weighed and mixed into a slurry by agitation.

\subsection{Determination of Pasting Properties}

Pasting properties of starch were measured using a Brabender Viscograph-E (Brabender GmbH \& Co. KG, Duisburg, Germany) at $85 \mathrm{rpm}$ and $700 \mathrm{cmg}$ torque. Slurries made up of $40 \mathrm{~g}$ starch and starch-gum mixture (adjusted to $14 \%$ moisture content) and $420 \mathrm{ml}$ distilled water added in the Viscograph-E canister. The slurry was heated from $30^{\circ} \mathrm{C}$ to $93^{\circ} \mathrm{C}$ at a rate of $1.5^{\circ} \mathrm{C} / \mathrm{min}$; held at $93^{\circ} \mathrm{C}$ for $15 \mathrm{~min}$; cooled to $30^{\circ} \mathrm{C}$ at $1.5^{\circ} \mathrm{C} / \mathrm{min}$ and finally held at $30^{\circ} \mathrm{C}$ for $15 \mathrm{~min}$. Resistance to stirring was recorded as viscosity in Brabender Units (BU). The pasting temperature $\left({ }^{\circ} \mathrm{C}\right)$, peak viscosity $(\mathrm{BU})$, breakdown viscosity (peak viscosity minus trough viscosity, BU), setback viscosity (final viscosity minus trough viscosity, $\mathrm{BU}$ ) and final viscosity (BU) were determined using the Viscograph-E correlation software as indicated in Figure 1. All the determinations were done in duplicate.

\subsection{Determination of Textural Properties}

The textural properties of the starch gels were determined by using back extrusion tests. Approximately $80 \mathrm{~g}$ of the slurries obtained from the Brabender Viscograph-E were poured into $50 \mathrm{~mm}$ diameter A/BE back extrusion containers (Stable Micro Systems, Surrey, UK). Back extrusion force was measured using TA. XT-plus Texture Analyzer (Stable Micro Systems, Surrey, UK) at the following TA settings: mode of measurement: force; load cell: $50 \mathrm{~kg}$; height calibration: $80 \mathrm{~mm}$; disc diameter: $45 \mathrm{~mm}$; pre-test speed: $1 \mathrm{~mm} / \mathrm{s}$; trigger force: $10 \mathrm{~g}$ : posttest speed: $10 \mathrm{~mm} / \mathrm{s}$; data acquisition rate: 200 pps; penetration distance: $30 \mathrm{~mm}$. Firmness (maximum positive force, $\mathrm{g}$ ), consistency (area of the positive region of curve, g.s), cohesiveness (maximum negative force, g) and work of cohesion 


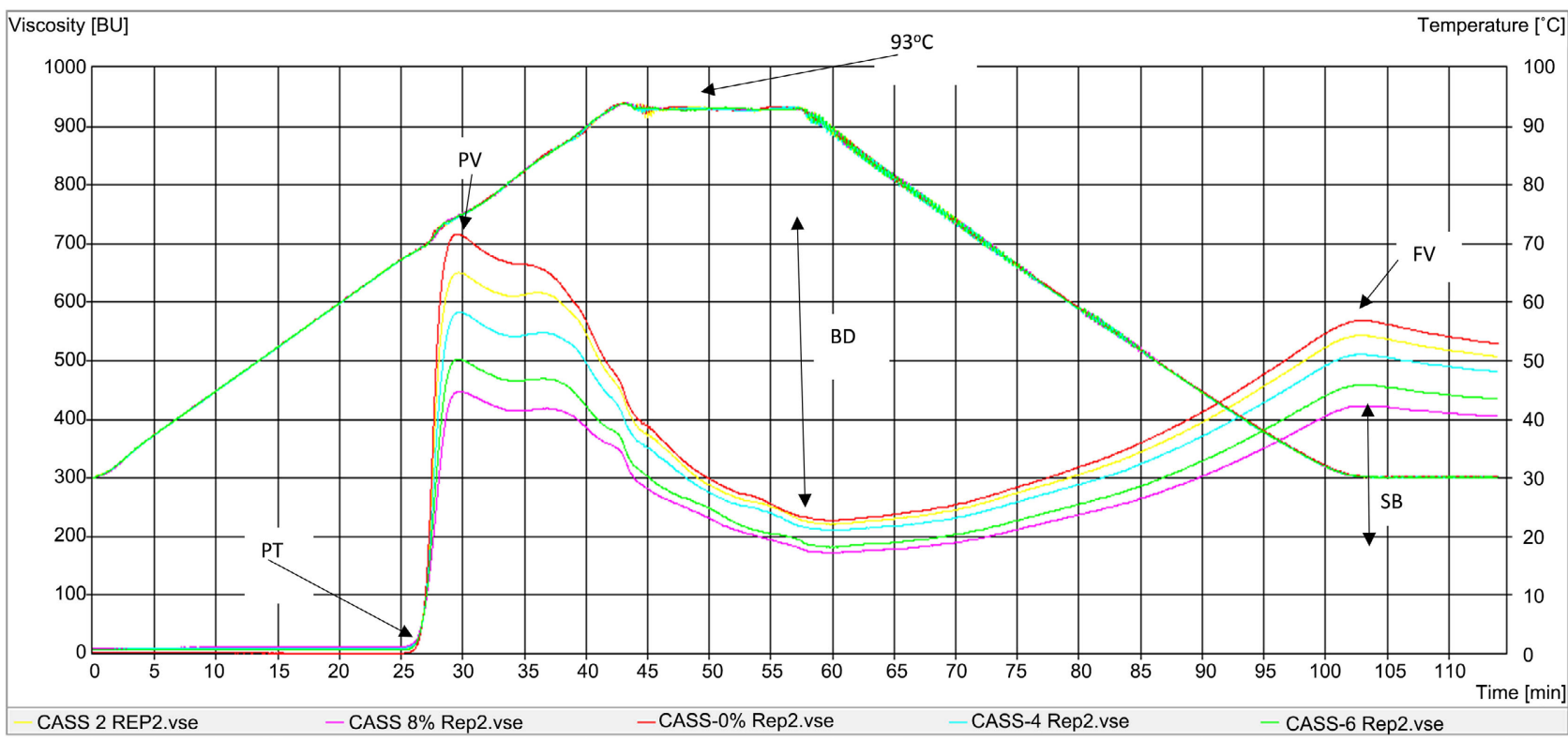

(a)

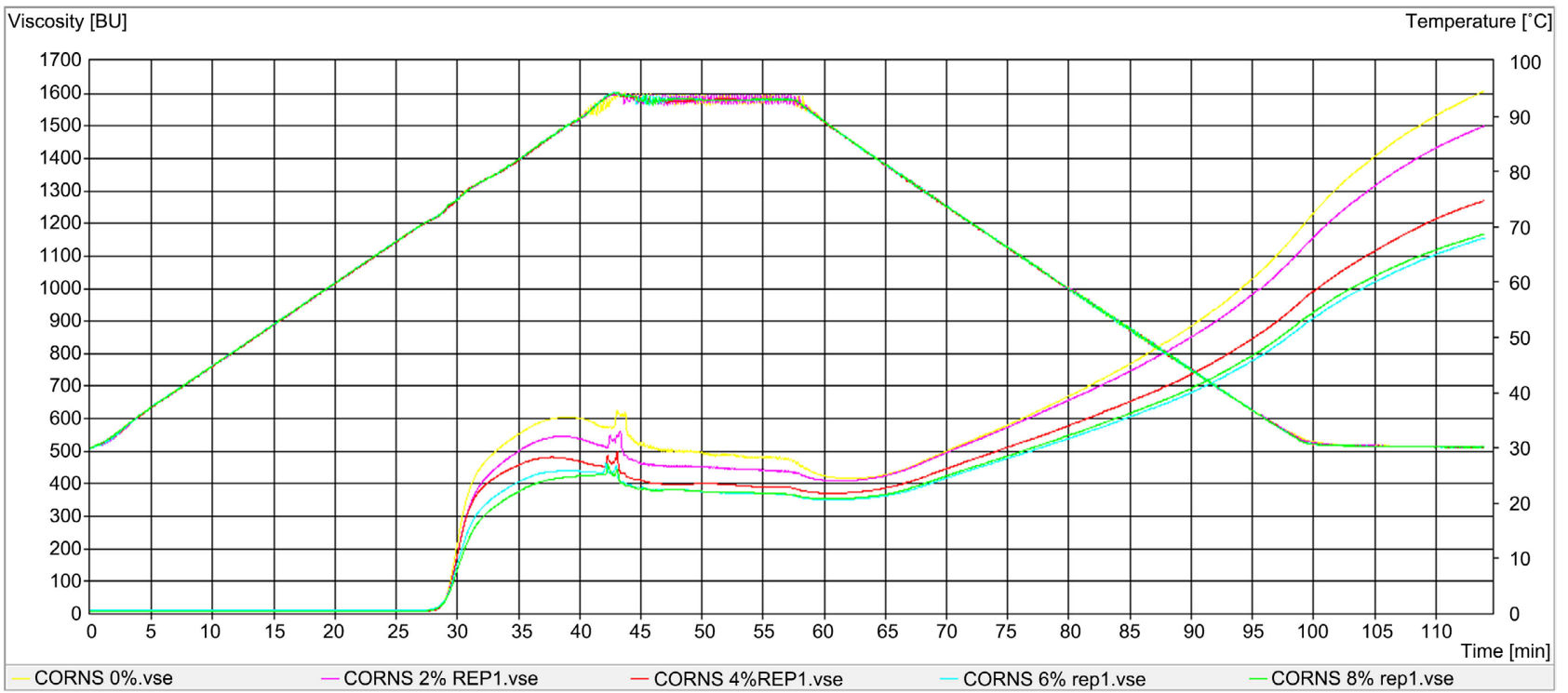

(b)

Figure 1. Viscograms indicating the effect of gum Arabic on pasting properties of cassava and corn starches. (a) Viscograms of cassava starch (CaS)-gum blends; (b) Viscograms of corn starch (CS)-gum blends.

(area of the negative region of the curve) were determined using Texture Analysis software. All the determinations were done in triplicate.

\subsection{Statistical Analysis}

Samples were analyzed in triplicate and data obtained was analyzed statistically using SAS software version 9.1 (SAS Institute and Cary, NC). Analysis of variance (ANOVA) was carried out to study the effect of gum Arabic on the pasting and textural properties. Pearson's correlation was done to establish the strength of relationship between pasting and textural properties. Post-hoc analy- 
sis employed the use of Tukeys honestly significant difference (HSD) test at $\mathrm{P}<$ 0.05 .

\section{Results}

\subsection{Pasting Properties of Corn and Cassava Starches}

The pasting behaviors of corn and cassava starches are shown in Table 1 and Figure 1. Corn starch (CS) displayed a significantly higher onset pasting temperature, final and setback viscosity values as compared to that of cassava starch (CaS) which displayed a higher peak and breakdown viscosity values. The effect of gum Arabic on the pasting parameters of cassava starch (CaS) and corn starch (CS) are shown in Table 2. Gum Arabic decreased significantly the viscosity parameters at higher substitution levels but no effect observed on the onset PT $\left(68.90^{\circ} \mathrm{C}\right.$ to $\left.68.65^{\circ} \mathrm{C}\right)$ and $\left(72.05^{\circ} \mathrm{C}\right.$ to $\left.71.85^{\circ} \mathrm{C}\right)$ for $\mathrm{CaS}$ and CS, respectively. Native corn and cassava starch (control samples) exhibited highest PV values $723.50 \mathrm{BU}$ and $636.50 \mathrm{BU}$ respectively. With increasing substitution levels of

Table 1. Pasting properties of corn and cassava starches.

\begin{tabular}{cccccc}
\hline Starch & $\begin{array}{c}\text { Onset pasting } \\
\text { temp (OPT) }\end{array}$ & $\begin{array}{c}\text { Peak viscosity } \\
(\mathrm{PV})\end{array}$ & $\begin{array}{c}\text { Final viscosity } \\
(\mathrm{FV})\end{array}$ & $\begin{array}{c}\text { Breakdown } \\
(\mathrm{BD})\end{array}$ & $\begin{array}{c}\text { Setback } \\
(\mathrm{SB})\end{array}$ \\
\hline Casava & $68.78 \pm 0.03^{\mathrm{b}}$ & $602.25 \pm 0.82^{\mathrm{a}}$ & $481.75 \pm 4.79^{\mathrm{b}}$ & $382.50 \pm 4.34^{\mathrm{a}}$ & $260.58 \pm 9.89^{\mathrm{b}}$ \\
Corn & $71.79 \pm 0.02^{\mathrm{a}}$ & $539.92 \pm 1.25^{\mathrm{b}}$ & $1426.26 \pm 6.19^{\mathrm{a}}$ & $117.67 \pm 7.70^{\mathrm{b}}$ & $645.00 \pm 3.25^{\mathrm{a}}$ \\
\hline
\end{tabular}

Means with the same letter along the column are not significantly different at $\mathrm{p}<0.05$.

Table 2. Pasting profile of cassava and corn starches at different concentrations of gum Arabic.

\begin{tabular}{|c|c|c|c|c|c|c|}
\hline Starch & GA (\%) & $\operatorname{PT}\left({ }^{\circ} \mathrm{C}\right)$ & $\mathrm{PV}(\mathrm{BU})$ & $\mathrm{FV}(\mathrm{BU})$ & $\mathrm{BD}(\mathrm{BU})$ & $\mathrm{SB}(\mathrm{BU})$ \\
\hline \multirow[t]{6}{*}{ Cassava } & 0.0 & $68.85 \pm 0.05^{\mathrm{a}}$ & $723.50 \pm 7.50^{\mathrm{a}}$ & $528.00 \pm 0.00^{\mathrm{a}}$ & $484.00 \pm 5.00^{\mathrm{a}}$ & $293.00 \pm 3.00^{\mathrm{a}}$ \\
\hline & 0.5 & $68.90 \pm 1.10^{\mathrm{a}}$ & $704.50 \pm 3.50^{\mathrm{a}}$ & $533.50 \pm 3.50^{\mathrm{a}}$ & $463.00 \pm 4.00^{\mathrm{a}}$ & $295.50 \pm 4.00^{\mathrm{a}}$ \\
\hline & 2.0 & $68.75 \pm 0.05^{\mathrm{a}}$ & $657.00 \pm 6.00^{\mathrm{b}}$ & $514.50 \pm 6.50^{\mathrm{a}}$ & $421.00 \pm 4.00^{\mathrm{b}}$ & $281.00 \pm 4.00^{\mathrm{a}}$ \\
\hline & 4.0 & $68.75 \pm 0.05^{\mathrm{a}}$ & $578.50 \pm 4.50^{c}$ & $477.50 \pm 3.50^{\mathrm{b}}$ & $360.00 \pm 2.00^{c}$ & $257.00 \pm 1.00^{\mathrm{b}}$ \\
\hline & 6.0 & $68.65 \pm 0.05^{\mathrm{a}}$ & $502.00 \pm 1.00^{\mathrm{d}}$ & $433.50 \pm 1.50^{c}$ & $301.50 \pm 4.50^{\mathrm{d}}$ & $227.00 \pm 5.00^{c}$ \\
\hline & 8.0 & $68.65 \pm 0.05^{\mathrm{a}}$ & $448.00 \pm 0.00^{\mathrm{e}}$ & $403.50 \pm 1.50^{\mathrm{d}}$ & $265.50 \pm 0.50^{\mathrm{e}}$ & $210.00 \pm 2.00^{c}$ \\
\hline \multirow[t]{6}{*}{ Corn } & 0.0 & $72.05 \pm 0.05^{\mathrm{a}}$ & $636.50 \pm 1.50^{\mathrm{a}}$ & $1633.00 \pm 5.00^{\mathrm{ab}}$ & $157.00 \pm 9.00^{\mathrm{a}}$ & $716.00 \pm 5.00^{\mathrm{ab}}$ \\
\hline & 0.5 & $72.00 \pm 0.00^{\mathrm{a}}$ & $619.50 \pm 0.50^{\mathrm{a}}$ & $1764.50 \pm 6.50^{\mathrm{a}}$ & $132.00 \pm 2.00^{\mathrm{ab}}$ & $812.00 \pm 2.00^{\mathrm{a}}$ \\
\hline & 2.0 & $71.95 \pm 0.05^{\mathrm{a}}$ & $559.00 \pm 4.00^{\mathrm{b}}$ & $1479.00 \pm 2.00^{\mathrm{b}}$ & $130.50 \pm 5.50^{\mathrm{b}}$ & $669.50 \pm 1.50^{\mathrm{b}}$ \\
\hline & 4.0 & $71.95 \pm 0.05^{\mathrm{a}}$ & $498.00 \pm 1.00^{c}$ & $1259.00 \pm 2.00^{\mathrm{bc}}$ & $110.00 \pm 0.00^{\mathrm{bc}}$ & $560.00 \pm 1.00^{c}$ \\
\hline & 6.0 & $72.00 \pm 0.00^{\mathrm{a}}$ & $463.50 \pm 0.50^{c}$ & $1187.50 \pm 0.50^{c}$ & $91.50 \pm 4.50^{c}$ & $536.00 \pm 2.00^{\mathrm{d}}$ \\
\hline & 8.0 & $71.85 \pm 0.05^{\mathrm{a}}$ & $463.00 \pm 3.00^{c}$ & $1237.00 \pm 7.00^{c}$ & $85.00 \pm 7.00^{c}$ & $576.00 \pm 3.00^{b c}$ \\
\hline
\end{tabular}

Means with the same letter along the column within the same starch source are not significantly different at $\mathrm{p}<0.05$. PT $=$ pasting temperature; $\mathrm{PV}=$ peak viscosity; $\mathrm{FV}$ = final viscosity; $\mathrm{BD}=$ breakdown viscosity; $\mathrm{SB}=$ setback viscosity; $\mathrm{BU}=\mathrm{Brabender}$ units; $\mathrm{GA}=$ Gum Arabic. 
$\mathrm{GA}$, the peak viscosity (PV) values decreased significantly. The same trend can be observed for the FV, BD and $\mathrm{SB}$ where a significant decrease with increasing substitution level of GA can be observed, though at lower levels (0.5\% and $2 \%)$ the viscosity parameters were not significantly different from the control sample (0\% GA).

\subsection{Textural Properties of Corn and Cassava Starches}

Textural properties of cassava and corn starches determined using texture analyzer (TA) is presented in Table 3 . The parameters obtained using TA were firmness, cohesiveness, consistency and work of cohesion. Corn starch gels had a significant higher firmness (769.89 g) and consistency (19,140.32 gs) mean values compared to cassava starch gels $85.43 \mathrm{~g}$ and 2016.33 gs respectively. On the other hand, CaS gels had a significant higher value on the cohesiveness and the work of cohesion compared to corn starch gels.

\subsection{Effect of Gum Arabic Level in Starch Material on Textural Properties}

The effect of GA on the textural properties of corn and cassava starches is shown in Figure 2. Gum Arabic had a significant effect on the firmness, consistency and work of cohesion of both CS and CaS gels. However, there was no significant effect of GA on the cohesiveness of both starch gels though 8\% GA level had the highest value $(-652.10 \mathrm{~g})$ and $0.5 \%$ had the least value $(-1082.08 \mathrm{~g})$ for CS gel while $6 \%$ GA level had the highest value $(-128.41 \mathrm{~g})$ and $0 \%$ had the least value $(-146.28 \mathrm{~g})$ for cassava starch gels. As the levels of gum increased from 0.5 to $8 \%$ there was a significant reduction on the firmness of CS gels as compared to CaS gels that showed no marked difference at lower $(0 \%, 0.5 \%, 2 \%)$ and higher (6\% and $8 \%)$ gum substitution levels. The firmness of $\mathrm{CaS}$ containing $8 \%$ gum was the highest $(94.32 \mathrm{~g}$ ), while it was the lowest in sample containing $2 \%$ gum (78.93 g) however, in the case of CS gels, the gum significantly reduced the firmness with $8 \%$ gum having the lowest value $(618.42 \mathrm{~g})$ while the control $0 \%$ gum had the highest value $(894.90 \mathrm{~g})$. There was a significant reduction in the consistency of CS gels as the levels increased from $0.5 \%$ to $8 \%$ however, there was no significant effect in the consistency of $\mathrm{CaS}$ gels as the level increased from $0 \%$ to $2.0 \%$ but as the level of GA was increased to $6 \%$ the consistency of

Table 3. Textural properties of starch material.

\begin{tabular}{ccccc}
\hline Material & $\begin{array}{c}\text { Firmness } \\
(\mathrm{max}+\mathrm{ve} \text { force }) \\
(\mathrm{g})\end{array}$ & $\begin{array}{c}\text { Consistency } \\
(\mathrm{mean}+\mathrm{ve} \text { area }) \\
(\mathrm{gs})\end{array}$ & $\begin{array}{c}\text { Cohesiveness } \\
(\mathrm{max}-\mathrm{ve} \text { force })\end{array}$ & $\begin{array}{c}\text { Work of cohesion } \\
(\mathrm{g})\end{array}$ \\
\hline Cassava starch & $85.43 \pm 1.67^{\mathrm{b}}$ & $2016.33 \pm 5.2^{\mathrm{b}}$ & $-135.86 \pm 2.19 \mathrm{a}$ & $-290.37 \pm 7.85^{\mathrm{a}}$ \\
Corn starch & $769.89 \pm 2.02^{\mathrm{a}}$ & $19,140.32 \pm 6.47^{\mathrm{a}}$ & $-826.96 \pm 3.39^{\mathrm{b}}$ & $-593.79 \pm 2.80^{\mathrm{b}}$ \\
\hline
\end{tabular}

Means with the same letter along the column are not significantly different at $\mathrm{p}<0.05$. $\mathrm{Max}+\mathrm{ve}=$ maximum positive; $\max -\mathrm{ve}=$ maximum negative. 


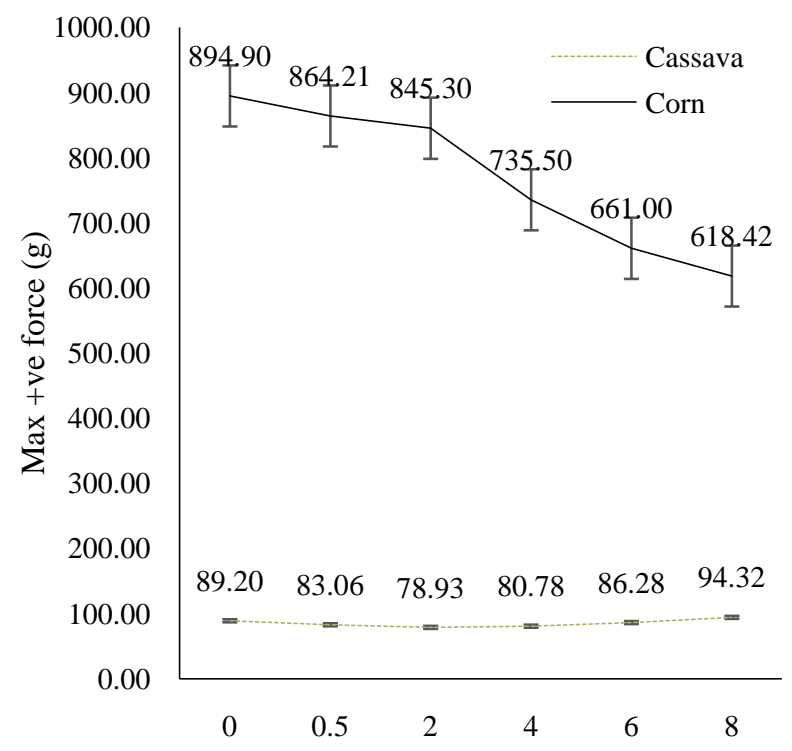

Gum Arabic (\%)

(a)

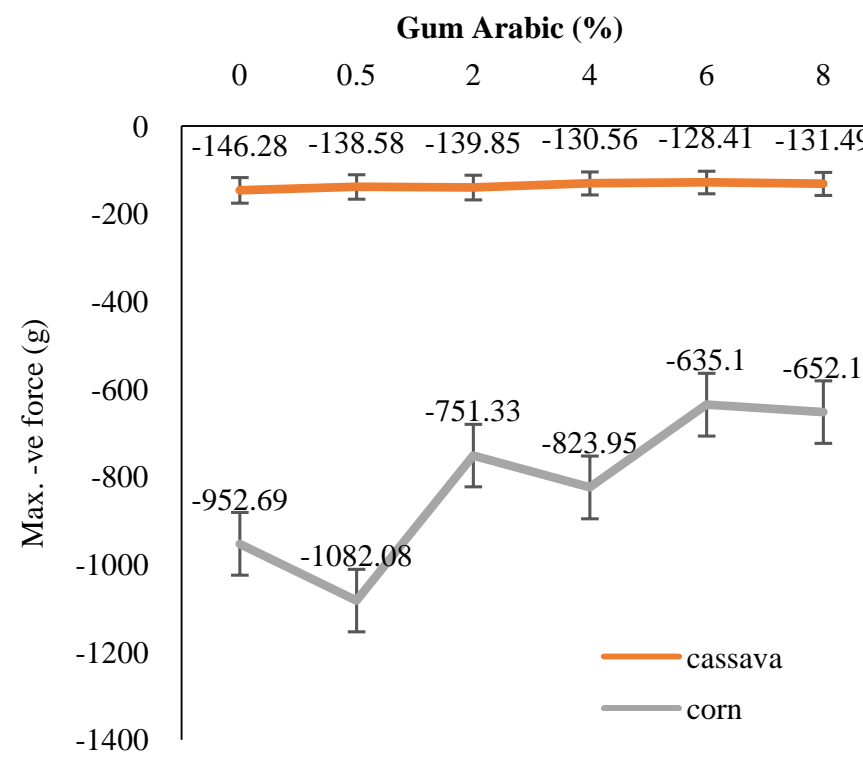

(c)

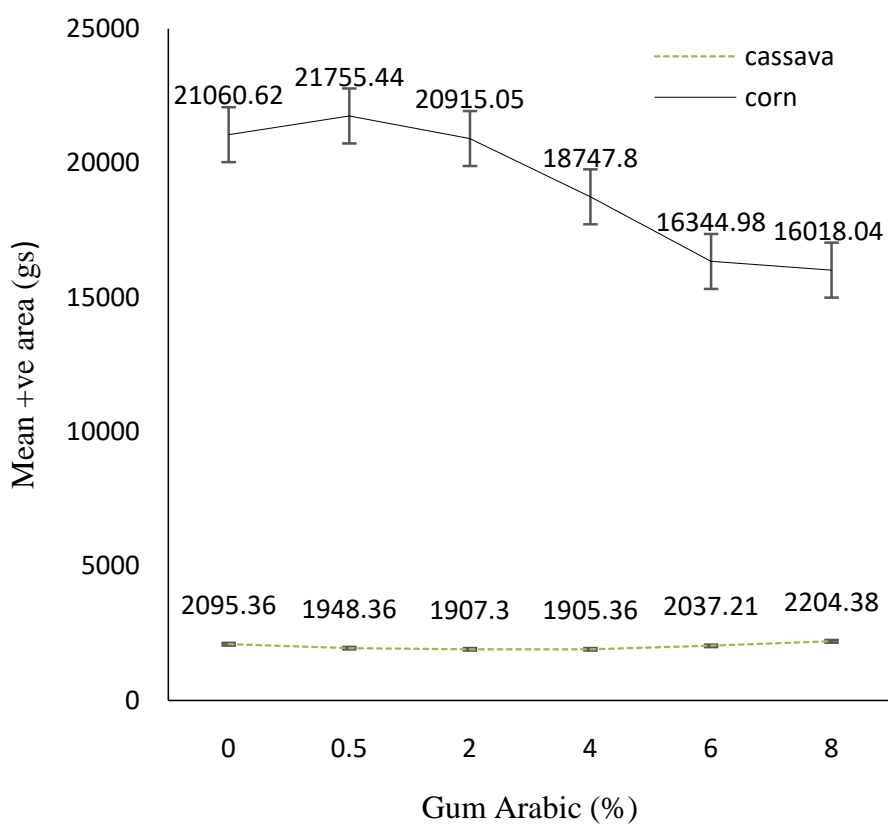

(b)

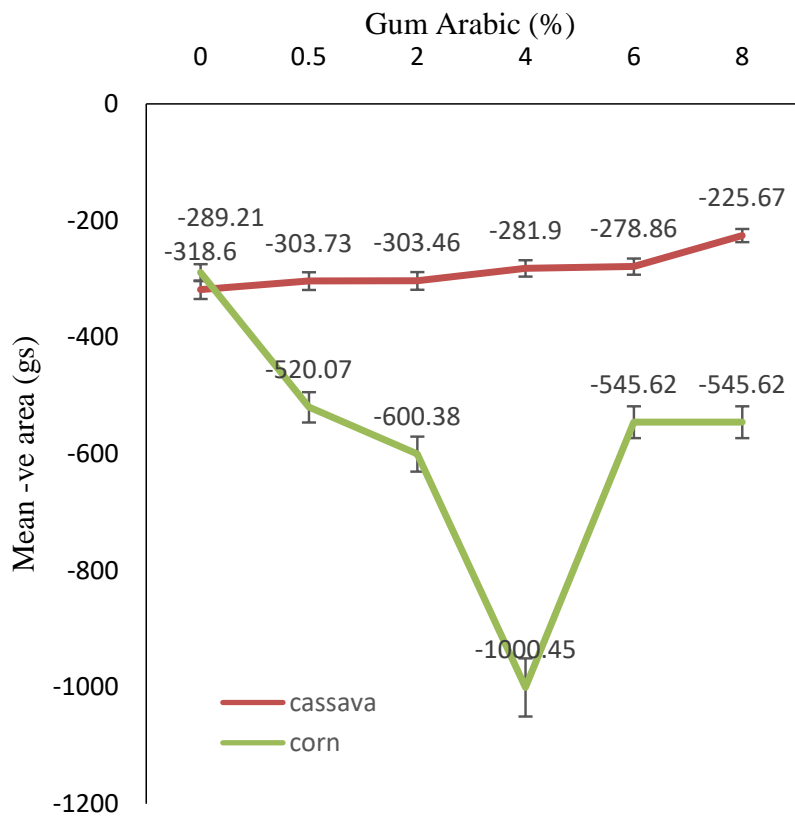

(d)

Figure 2. Effect of gum Arabic level on textural properties of cassava and corn starch gels. (a) Effect of gum Arabic on firmness of corn and cassava starches; (b) Effect of gum Arabic on consistency of corn and cassava starches; (c) Effect of gum Arabic on cohesiveness of corn and cassava starches; (d) Effect of gum Arabic on work of cohesion of corn and cassava starches.

the starch increased though no difference-was observed between $6 \%$ to $8 \% \mathrm{GA}$ level. Similarly, the presence of GA in CaS gels showed a slight increase in the work of cohesion. In the case of CS gels such changes were not found, however, a significant decrease in values of this parameter was observed for samples with $0.5 \%, 4 \%$ and $6 \%$ GA levels. 


\subsection{Effect of Gum Arabic on the Relationship between Pasting and Textural Properties of Corn and Cassava Starches}

Correlation relationship between textural and pasting properties of corn and cassava starches with gum Arabic is shown in Table 4. All the properties showed medium to strong positive and negative significant correlation coefficients except peak viscosity which exhibited a non-significant relationship with all properties except breakdown viscosity. Starch gels cohesiveness and work of cohesion textural properties significantly had a strong negative correlation with onset pasting temperature, final viscosity and setback viscosity but showed significantly positive correlation with breakdown viscosity. On contrary, firmness and consistency had a significant positive correlation with onset pasting temperature, final viscosity and setback viscosity but showed significantly negative correlation with breakdown viscosity. Firmness and consistency of starches were significantly positively correlated $(r=0.999)$ while cohesiveness and work of cohesion had a significantly medium positive correlation $(r=0.582)$. Among pasting properties, only breakdown viscosity exhibited a significant negative correlation with onset pasting temperature $(r=-0.895)$, final viscosity $(r=-0.806)$ and setback viscosity $(r=-0.776)$.

\section{Discussion}

\subsection{Effect of GA on the Pasting Properties of Cassava and Corn Starches}

The process of pasting occurs with continued heating of starch granules in the presence of excess water and involves continued granule swelling, additional leaching of dissolved starch polymer molecules. The cohesive forces in the swollen granules become excessively weakened and the structure of the paste collapses [19]. Swelling of granules, accompanied by leaching of amylose, increases

Table 4. Correlation coefficients of textural and pasting properties of corn and cassava starches with gum Arabic.

\begin{tabular}{|c|c|c|c|c|c|c|c|c|c|}
\hline & Firmness & Consistency & Cohesiveness & WOC & OPT & PV & FV & Breakdown & Setback \\
\hline Firmness & 1.000 & $0.999^{* * *}$ & $-0.969^{* * *}$ & $-0.597^{\star \star}$ & $0.979^{* * *}$ & $-0.222 \mathrm{~ns}$ & $0.984^{* * *}$ & $-0.866^{* * *}$ & $0.969^{* * *}$ \\
\hline Consistency & & 1.000 & $-0.972^{\star * *}$ & $-0.624^{\star * *}$ & $0.983^{\star * *}$ & $-0.239 \mathrm{~ns}$ & $0.983^{\star * *}$ & $-0.875^{\star * *}$ & $0.966^{* * *}$ \\
\hline Cohesiveness & & & 1.000 & $0.582^{\star * *}$ & $-0.943^{\star * *}$ & $0.170 \mathrm{~ns}$ & $-0.970^{* * *}$ & $0.822^{* * *}$ & $-0.958^{\star * \star}$ \\
\hline WOC & & & & 1.000 & $-0.659^{\star * *}$ & $0.372 \mathrm{~ns}$ & $-0.523^{\star *}$ & $0.617^{\star * *}$ & $-0.508^{\star}$ \\
\hline OPT & & & & & 1.000 & $-0.300 \mathrm{~ns}$ & $0.952^{* * *}$ & $-0.895^{\star * *}$ & $0.938^{* * *}$ \\
\hline PV & & & & & & 1.000 & $-0.105 n s$ & $0.671^{* * *}$ & $-0.059 \mathrm{~ns}$ \\
\hline $\mathrm{FV}$ & & & & & & & 1.000 & $-0.806^{* * *}$ & $0.997^{\star * *}$ \\
\hline Breakdown & & & & & & & & 1.000 & $-0.776^{\star * *}$ \\
\hline Setback & & & & & & & & & 1.000 \\
\hline
\end{tabular}

Key: WOC $=$ Work of Cohesion; OPT $=$ Onset Pasting Temperature; PV $=$ Peak Viscosity; FV = Final Viscosity; ${ }^{\star * *}=$ Significance level is $\mathrm{p}=0.001 ;^{* *}=$ Significance level is $\mathrm{p}=0.01 ;^{*}=$ Significance level is $\mathrm{p}=0.05 ; \mathrm{ns}=$ Not significant at $\mathrm{p}<0.05$. 
viscosity, while granules may rupture during further heating, resulting in a decrease in viscosity. Pasting temperature is an indicator of minimum energy required to cook starch containing food products. It is also a point where viscosity starts increasing [20]. Cassava starch swell to a greater extent than CS as depicted by the peak viscosity though CS is more stable than $\mathrm{CaS}$ as depicted by the final, break down and set back viscosities as shown in Table 1. This difference may be attributed to the higher amylose content (25\%) with lipids in CS that form a complex restricting swelling as compared with CaS with relatively lower amylose content (17\%).

This agrees with previous study [21] that reported that starch consisting of a larger amylose-content, particularly with the presence of lipids, displays a higher PT and a lower PV because amylose restricts the swelling of starch granules during heating and shearing. Similarly, according to [22], tuber (potato) and root (tapioca/cassava) starches have weak intermolecular bonding and swell greatly to give high viscosity pastes but if shear is applied, the viscosity decreases quickly because the highly swollen granules break easily. The functional properties of starches may vary depending on their source, structure, grain size, grain shape, amylose content, chain length of amylopectin and methods of extraction [17].

It has been observed that addition of hydrocolloids alters the pasting properties of starch [1] [8] [23]. The pasting temperature, $68^{\circ} \mathrm{C}$ and $72^{\circ} \mathrm{C}$ for $\mathrm{CaS}$ and CS respectively, was not affected by the addition of GA depicting that this gum neither quickened nor delayed the gelatinization process as shown in Table 2. Similar results were reported by [24] where acacia gum (GA) had neither positive nor negative effect on the pasting temperature of water chestnut starch. The high pasting temperature of CS indicates that its more resistant against swelling than $\mathrm{CaS}$ and this can be attributed to the amylose lipid complex in the former. According to [19], native potato and tapioca starches have weak intermolecular bonding and gelatinize easily to produce high-viscosity pastes that thin rapidly with moderate shear. Peak viscosity (PV) is the point at which maximum swelling of starch granule is observed. Corn starch depicted a relatively lower PV (539 BU) than cassava starch (602 BU) and this may be due to moderate swelling of the granules (Table 1). The decrease in PV in the present study, can be attributed to the limited granule swelling and reduced granule association caused by coating of starch granules with GA as shown in Table 2. Similar observation was made by [8] who clearly demonstrated that addition of GA resulted in a significant $(\mathrm{P}<0.05)$ decrease in peak viscosity, relative breakdown and total setback values of tapioca starch, this may be useful for stability during storage. Previous study [25] reported similar findings were in low gum levels, gum Arabic and xanthan gum exhibited lower pasting properties of wheat and maize starches. Contrary findings were reported by [26] whose results indicated a significant increase in pasting viscosities of starch as a result of hydrocolloids addition regardless of type and ratio of hydrocolloids added.

The change in the PV during heating clearly indicated that there was starch 
gelatinization upon heating. It was also visible that there was a strong impact of the addition of GA to the CS and CaS dispersions. Gum Arabic, at higher substitution levels, could presumably have covered most of the starch granules and promoted granules association, which restricted swelling of the granules and limited the increase in viscosity during pasting. According to [20], addition of Arabic gum to sweet potato starch caused the maximum reduction in the peak viscosity and even though gum Arabic exhibited the least pasting temperature, it had the highest setback among the other gums thus can significantly reduce retrogradation process. Most of the hydrocolloids frequently used increase the viscosity but the hydrocolloids with lower molecular mass may lead to a decrease in the viscosity as observed in the case of okra [27] and corn fiber gum [28], which may be useful in terms of controlling viscosity of mixture/dispersions.

The reduction in peak viscosity may be due to retardation of granule destruction and leaching of amylose, when negatively charged starch solution were heated with anionic gums. Also, such effects can be due to interactions between leached amylose molecules and the gum used [19] [29]. The effect of GA on final viscosity of starches was also established. Final viscosity (FV) measures the stability of gelatinized starch and the ability of a starch to form a paste or gel after cooling [30]. The current study revealed a decrease in the FV for both starches at $8 \%$ gum concentration though CS has significant higher $\mathrm{FV}$ value than $\mathrm{CaS}$ (1237 BU and $403 \mathrm{BU}$ respectively) as shown in Table 2. This indicates that GA can be incorporated in less viscous foods. The decrease in FV in the presence of a hydrocolloid at varying concentrations had also been observed by various researchers [23] [27].

During pasting, considerable continued granule swelling and leaching of starch polymer (primarily amylose) molecules occurs. During the $93^{\circ} \mathrm{C}$ hold as shown in Figure 1, the fragile swollen granules disintegrate under the shear conditions of the instrument and the viscosity decreases to a trough viscosity a process called breakdown. Breakdown viscosity essentially measures the difference between peak and trough viscosities. The breakdown is related to the stability of the granules against mechanical shear and heat upon continuous cooking [31]. The results for the addition of GA proved that the interaction between the gum and both starches affected the swollen starch granules. The reduced BD with the addition of GA indicates that the swelling and shear-thinning of starch was retarded during pasting. Low breakdown value of starch suggests the starch granules are more stable during cooking and by extension a stronger cross-linking within the starch granules. Consequently, corn starch is more stable than $\mathrm{CaS}$ as shown in Table 2 and Figure 1, this may be attributed to the tightening of CS granules that resist breakdown as compared with $\mathrm{CaS}$ granules that are more fragile as subjected to mechanical forces. Also, the low breakdown is associated with less starch granule rupture and can therefore guarantee a more stable cooked paste [22].

As shown in Table 2 , the setback value decreased significantly $(\mathrm{p}<0.05)$ with increased GA concentrations recording lower setback value, $210 \mathrm{BU}$ and $576 \mathrm{BU}$ 
for CaS and CS respectively. Consequently, CaS can resist retrogradation tendency as compared to CS due to low setback value. This result indicates that the addition of Arabic gum could retard retrogradation hence improve the storage properties of starch-based products. Comparable observations were reported by [23] for starch-Agbagoma pectin mixtures and [27] for rice and sorghum starches. Setback is the cooling phase of the mixture during pasting in which a reassociation between the starch molecules occurs to a greater or lesser degree and also a lower setback viscosity indicates higher resistance to retrogradation [7]. Correspondingly, [8] also found that GA lowered the PV and swelling power leading to a delay of retrogradation. The reduction of starch setback might be due to the competition of hydrocolloids and amylose molecules to establish an intermolecular connection during cooling, thus decreasing the quantity of amylase-amylose interactions that are fundamental to starch retrogradation [32].

\subsection{Effect of GA on the Textural Properties of Cassava and Corn Starches}

Cassava and corn starches showed variation in textural parameters which may be attributed to differences in starch granule size, shape and amylose content as shown in Table 3. Corn starch displayed higher firmness values as compared to $\mathrm{CaS}$ gels which agrees with the fact that the crystalline size and association within the maize granules are of a higher order of magnitude than that in cassava granules [5]. According to [5] cassava (tapioca) starch produces clear, cohesive pastes that gel slowly with time while native corn, rice and wheat starches form opaque, gelled pastes that have a slight cereal flavour. The firmness of CaS gels slightly decreased as a result of replacement of starch with gum Arabic (GA) however, it increased at higher levels used (8\%) though it showed no significant difference with the native CaS (0\%) (Figure 2(a)). These slight increase in the firmness of the gels may be due to increased effective concentration of starch by the immobilization of water molecules by the macro-molecules of the gum. On the other hand, the firmness of corn starch gels was significantly decreased with addition of GA $(\mathrm{p}<0.05)$. This can be attributed to the fact that the strongly swollen granules become softer and disintegrate, consequently decreasing starch firmness.

A previous study reported similar results where the addition of hydrocolloids, particularly xanthan gum and GA, decreased the hardness of the pastes compared with that of the native corn starch [33]. The firmness reduced further for corn starch gels when the amount of GA was increased, suggesting that the addition of hydrocolloids reduces the gel strength, probably because hydrocolloids hamper the amylose molecular gathering and rearrangement, weakening the interaction of amylose molecules [33] [34]. Our findings also concur with those reported by [35] where the addition of xanthan gum to arrow root starch gels produced the opposite effect on gel hardness, showing great hardness at very low levels, which gradually decreased as the hydrocolloid levels increased. Conse- 
quently, according to [17] reported that higher levels of gum (i.e., 9\% and 12\%) decreased gel hardness when compared to $6 \%$ and this could be attributed to the starch dilution effect. The dilution effect can be explained as reduction of amylose contents in the blends with increasing the gum level. Previous study [25] reported that gel hardness/firmness depends on the starch-hydrocolloid combination. The relative concentration of starch and gum affects the hardness of the mixed gels by limiting the movement of water molecules and interaction between the hydroxyl group of the gum and starch molecules. The degree of polymerization and linearity of dispersed particles and interactions between molecules in the gel system have an important role in the textural properties including hardness/firmness of gel [10] [36].

Presence of GA in cassava starch gels resulted in slight increase in consistency which can indicate strengthened structure of the gels that resulted from interactions between the polymers. The peak or maximum force is taken as a measurement of consistency during textural measurements of starch gels by back extrusion (Figure 2(b)), the higher the value the thicker the consistency of the sample [37]. In the case of corn starch gels consistency of corn starch decreased with an increase in the levels of GA. The consistency of corn starch gels at higher gum concentration (8\%) was significantly lower than the native corn starch and this may be attributed to the fact that the gum helps to weaken the amylose networking by impeding between the amylose molecules. These results also indicate that an increase in the concentration of the gum reduces the strength of the internal bonds hence decreasing the resistance to structural disintegration. This behavior can be attributed to reduced leaching of amylose molecules responsible for strengthening the internal bonds of starch gels [11] [20] [35]. It is worth noting that when comparing cassava and corn starch gels without GA, the cassava gel strength occurred to be ten times less than that of the CS gel while the presence of GA particularly at the lower substitution levels with starch resulted in reduction of differences in the strength values of the respective gels.

The maximum negative force is taken as an indication of cohesiveness of the sample therefore the more negative the value the more "cohesive" is the sample. Cohesiveness indicates the strength of bonds which includes a mutual effect of cohesive and adhesive forces along with elasticity and viscosity [20]. The present study findings shows that gum Arabic did not have an impact on the cohesiveness of both starches' however, corn starch gel was more cohesive than cassava starch gel and this could be due to high amylose content in corn starch (Figure 2(c)). This behavior can be explained by the same interactions that influenced the firmness and consistency of the starches with added GA for instance coating the granules, restricting swelling and a reduction in leaching of amylose also as suggested by [31] for xanthan gum, however this should be further investigated. Similarly, findings reported by [36] on the influence of cassia gum on textural properties of potato and corn starch gels, showed that for all the parameters determined, potato starch gel in most cases occurred to be lower than those of re- 
spective corn starch gels. The area of the negative region of the curve may be referred to as the work of cohesion and the higher the value the more resistant to withdrawal the sample which is an indication of the consistency or viscosity of the sample [37] [38]. There was an increase in the work of cohesion for CaS gels as compared to CS gels (Figure 2(d)). It appears that CS gels require considerably more force to penetrate to the same depth as CaS gels may be attributed to strong associative forces between CS granules. According to [39] the addition of $1.5 \%$ Arabic gum was the most effective in reducing the in vitro starch digestibility and improving the cooking properties of noodles.

\subsection{Relationship between Pasting and Textural Properties}

The effect of gum Arabic on the functionality of cassava and corn starches has been examined by determining the pasting and textural properties. Regression analysis (Table 4) showed a medium to strong positive and negative significant correlation coefficients between textural parameters (firmness, consistency, cohesiveness and work of cohesion) and viscosity parameters. However, the peak viscosity did not significantly correlate with any of the textural parameters which may indicate granule swelling restriction and weakening of starch granule associated forces, which in turn makes them susceptible to breakdown resulting in weak gel formation.

Firmness and consistency significantly correlated with setback and the final viscosity which shows that the greater the ability of a starch to form a paste or gel and the recovery of viscosity of the starch paste during cooling thus the greater the energy needed to penetrate or deform the gel. This is in agreement with observed results by [36] who found correlations between hardness and setback viscosity with cassia gum. The breakdown values significantly negatively correlated with firmness and consistency $(r=-0.866$ and $r=-0.875)$ indicating retardation of starch swelling however onset pasting temperature significantly positively correlated with the afore mentioned texture parameters which may indicate more energy required to achieve stability of the pastes/gels. Values of the cohesiveness and work of cohesion were significantly strongly negatively correlated with onset pasting temperature, final viscosity and setback viscosity values but depicted significantly positive correlation with breakdown viscosity. This may be attributed to weakening of internal bonds of starch gels resulting to viscosity loss and elasticity of the sample due to granule swelling restriction by gum Arabic. These findings are consistent with previous reports [8] [11] [16] on interactions between starch and gums.

\section{Conclusion}

The interactions of gum Arabic with native starch depended both on the kind of starch, amylose content and the gum level. Substituting part of the starch, both cassava and corn, with gum Arabic resulted in modification of pasting characteristics of the starch. All the viscosity parameters decreased with increasing levels 
of gum however the onset pasting temperature was not affected. Presence of gum Arabic in starch systems also contributed to the changes in textural properties of the gels. Textural analysis results suggested that firmness and consistency was reduced for corn starch by the addition of GA while there was slight increase for cassava starch, which reveals the inhibition of amylose retrogradation. Significant positive correlations were observed between firmness and consistency with pasting temperature, final and setback viscosities. Consequently, the substantial reduction in setback viscosity implies that GA is suitable for retarding retrogradation; the cause of undesirable textural characteristics in starch-rich foods. The results of this study indicate the possibility of use of mixtures of native starch with gum Arabic as an alternative modifier to enhance stability and functionality of starchy foods. Thus, we recommend further studies on inclusion of GA from Acacia senegal var. kerensis in specific starch-based food products.

\section{Acknowledgements}

This study was funded through a research grant from the Center of Excellence in Sustainable Agriculture and Agribusiness Management (CESAAM), Egerton University, Kenya. The authors extend their appreciation to the Kenya Industrial Research and Development Institute (KIRDI), Nairobi, Kenya for availing the facilities and expertise that made the analyses possible. Special thanks also go to $\mathrm{Mr}$. Wafula for great insights especially in data analysis.

\section{Conflicts of Interest}

The authors declare no conflict of interest.

\section{References}

[1] Mahmood, K., Kamilah, H., Shang, P.L., Sulaiman, S., Ariffin, F. and Alias, A.K. (2017) A Review: Interaction of Starch/Non-Starch Hydrocolloid Blending and the Recent Food Applications. Food Bioscience, 19, 110-120. https://doi.org/10.1016/j.fbio.2017.05.006

[2] Yazid, N.S.M., Abdullah, N., Muhammad, N. and Matias-Peralta, H.M. (2018) Application of Starch and Starch-Based Products in Food Industry. Journal of Science and Technology, 10, 144-174. https://doi.org/10.30880/jst.2018.10.02.023

[3] Hussain, S. (2015) Native Rice Starch and Linseed Gum Blends: Effect on the Pasting, Thermal and Rheological Properties. Czech Journal of Food Science, 33, 556-563. https://doi.org/10.17221/243/2015-CJFS

[4] Oluwole, O., Akinwale, T., Adesioye, T., Odediran, O., Anuoluwatelemi, J., Ibidapo, O., Owolabi, F., Owolabi, S. and Kosoko, S. (2016) Some Functional Properties of Flours from Commonly Consumed Selected Nigerian Food Crops. International Research Journal of Agricultural and Food Sciences, 1, 92-98.

[5] BeMiller, J. and Whistler, R. (2009) Starch: Chemistry and Technology. 3rd Edition. Academic Press, Cambridge, MA, 374-564.

[6] Opondo, F., Owuor, G., Mshenga, P., Louw, A. and Jordan, D. (2020) Estimation of the Effect of Cassava Commercialization on Different Household Income Measurements in Kilifi County, Kenya. Journal of Sustainable Development, 13, 44-58. 
[7] Sharma, R., Oberoi, D.P.S., Sogi, D.S. and Gill, B.S. (2009) Effect of Sugar and Gums on the Pasting Properties of Cassava Starch. Journal of Food Processing and Preservation, 33, 401-414. https://doi.org/10.1111/j.1745-4549.2008.00283.x

[8] Chen, H.M., Fu, X. and Luo, Z.G. (2015) Effect of Gum Arabic on Freeze-Thaw Stability, Pasting and Rheological Properties of Tapioca Starch and Its Derivatives. Food Hydrocolloids, 51, 355-360. https://doi.org/10.1016/j.foodhyd.2015.05.034

[9] Bertolini, A.C. (2010) Starches: Characterization, Properties, and Applications. CRC Press, Boca Raton.

[10] Borries-Medrano, E.V., Jaime-Fonseca, M.R. and Aguilar-Méndez, M.A. (2018) Tapioca Starch-Galactomannan Systems: Comparative Studies of Rheological and Textural Properties. International Journal of Biological Macromolecules, 122, 1173-1183.

[11] Chaisawang, M. and Suphantharika, M. (2006) Pasting and Rheological Properties of Native and Anionic Tapioca Starches as Modified by Guar Gum and Xanthan Gum. Food Hydrocolloids, 20, 641-649.

https://doi.org/10.1016/j.foodhyd.2005.06.003

[12] Marta, H., Cahyana, Y. and Djali, M. (2020) The Effect of Starch-Hydrocolloid Interaction on Starch Digestibility, Pasting and Physicochemical Properties: A Review. Journal of Earth and Environmental Science, 443, Article ID: 012084. https://doi.org/10.1088/1755-1315/443/1/012084

[13] Varela, M.S., Navarro, A.S. and Yamul, D.K. (2016) Effect of Hydrocolloids on the Properties of Wheat/Potato Starch Mixtures. Starch-Stärke, 68, 753-761.

https://doi.org/10.1002/star.201400257

[14] Castellani, O., Guibert, D., Al-Assaf, S., Axelos, M., Phillips, G.O. and Anton, M. (2010) Hydrocolloids with Emulsifying Capacity. Part 1-Emulsifying Properties and Interfacial Characteristics of Conventional (Acacia senegal (L.) Willd. var. senegal) and Matured (Acacia (sen) SUPER GUM ${ }^{\mathrm{TM}}$ ) Acacia senegal. Food Hydrocolloids, 24,193-199. https://doi.org/10.1016/j.foodhyd.2009.09.005

[15] Saha, D. and Bhattacharya, S. (2010) Hydrocolloids as Thickening and Gelling Agents in Food: A Critical Review. Journal of Food Science and Technology, 47, 587-597. https://doi.org/10.1007/s13197-010-0162-6

[16] Singh, A., Geveke, D.J. and Yadav, M.P. (2016) Improvement of Rheological, Thermal and Functional Properties of Tapioca Starch by Using Gum Arabic. LWT-Food Science and Technology, 80, 155-162. https://doi.org/10.1016/j.lwt.2016.07.059

[17] Hussain, S., Mohamed, A.A., Alamri, M.S., Ibraheem, M.A., Abdo Qasem, A.A., Shahzad, S.A., Ibrahim A. and Ababtain, A.A. (2020) Use of Gum Cordia (Cordia myxa) as a Natural Starch Modifier; Effect on Pasting, Thermal, Textural, and Rheological Properties of Corn Starch. Foods, 9, Article No. 909. https://doi.org/10.3390/foods 9070909

[18] Kaur, H., Gill, B.S. and Karwasra, B.L. (2018) In Vitro Digestibility, Pasting, and Structural Properties of Starches from Different Cereals. International Journal of Food Properties, 21, 70-85. https://doi.org/10.1080/10942912.2018.1439955

[19] BeMiller, J.N. (2011) Pasting, Paste, and Gel Properties of Starch Hydrocolloid Combinations. Carbohydrate Polymer, 86, 386-423. https://doi.org/10.1016/j.carbpol.2011.05.064

[20] Shahzad, S.A., Hussain, S., Alamri, M.S., Mohamed, A.A., Ahmed, A.S., Ibraheem, M.A., Akram, A. and Abdo Qasem, A.A. (2019) Use of Hydrocolloid Gums to Modify the Pasting, Thermal, Rheological, and Textural Properties of Sweet Potato Starch. International Journal of Polymer Science, 2019, Article ID: 6308591. https://doi.org/10.1155/2019/6308591 
[21] Ai, Y., Hasjim, J. and Jane, J. (2013) Effects of Lipids on Enzymatic Hydrolysis and Physical Properties of Starch. Carbohydrate Polymers, 92, 120-127. https://doi.org/10.1016/j.carbpol.2012.08.092

[22] Damodaran, S., Parkin, K. and Fennema, O.R. (2008) Fennemas's Food Chemistry (Food Science and Technology). 4th Edition, CRC Press, New York, 120-121.

[23] Bawa, N.M., Agbenorhevi, J.K., Kpodo, F.M. and Sampson, G.O. (2020) Pasting Properties of Starch-Okra Pectin Mixed System. CyTA-Journal of Food, 18, 742-746. https://doi.org/10.1080/19476337.2020.1838616

[24] Lutfi, Z., Nawab, A., Alam, F., Hasnain, A. and Haider, S.Z. (2017) Influence of Xanthan, Guar, CMC and Gum Acacia on Functional Properties of Water Chestnut (Trapa bispinosa) Starch. International Journal of Biological Macromolecules, 103, 220-225. https://doi.org/10.1016/j.ijbiomac.2017.05.046

[25] Song, J.Y., Kim, Y.C. and Shin, M. (2008) Textural Properties and Structures of Wheat and Maize Starch-Gum Mixed Gels during Storage. Journal of Food Science and Biotechnology, 17, 20-25.

[26] Saleh, M., Ajo, R., Al-Ismail, K. and Ondier, G. (2016) Effects of Hydrocolloids on Acorn Starch Physical Properties. Starch-Stärke, 68, 1169-1179. https://doi.org/10.1002/star.201500304

[27] Alamri, M.S., Mohamed, A.A. and Hussain, S. (2012) Effect of Okra Gum on the Pasting, Thermal and Viscous Properties of Rice and Sorghum Starches. Carbohydrate Polymers, 89, 199-207. https://doi.org/10.1016/j.carbpol.2012.02.071

[28] Qiu, S., Yadav, M.P., Chen, H., Liu, Y., Tatsumi, E. and Yin, L. (2015) Effects of Corn Fiber Gum (CFG) on the Pasting and Thermal Behaviors of Maize Starch. Carbohydrate Polymers, 115, 246-252. https://doi.org/10.1016/j.carbpol.2014.08.071

[29] Shi, X. and BeMiller, J.N. (2002) Effects of Food Gums on Viscosities of Starch Suspensions during Pasting. Carbohydrate Polymers, 50, 7-18. https://doi.org/10.1016/S0144-8617(01)00369-1

[30] Shimelis, E.A., Meaza, M. and Rakshit, S. (2006) Physico-Chemical Properties, Pasting Behavior and Functional Characteristics of Flours and Starches from Improved Bean (Phaseolus vulgaris L.) Varieties Grown in East Africa. CIGR E-Journals, 8, $1-18$.

[31] Ribotta, P.D., Pérez, G.T., Añón, M.C. and León, A.E. (2010) Optimization of Additive Combination for Improved Soy-Wheat Bread Quality. Food and Bioprocess Technology, 3, 395-405. https://doi.org/10.1007/s11947-008-0080-Z

[32] Leite, T.D., Joel, F.N., Lúcia, B.P., Célia, M. and Landi, F. (2012) Effect of Addition of Different Hydrocolloids on Pasting, Thermal and Rheological Properties of Cassava Starch. Food Science and Technology, 32, 579-587. https://doi.org/10.1590/S0101-20612012005000074

[33] He, H., Zhang, Y., Hong, Y. and Gu, Z. (2014) Effects of Hydrocolloids on Corn Starch Retrogradation. Starch-Stärke, 67, 348-354.

[34] Zheng, Y., Sun, W., Yang, W., Chen, S., Liu, D., Tian, J. and Ye, X. (2020) The Influence of Xanthan Gum on Rheological Properties and in Vitro Digestibility of Kudzu (Pueraria lobata) Starch. Starch-Stärke, 72, Article ID: 1900139. https://doi.org/10.1002/star.201900139

[35] da Silva Costa, R.A., Bonomo, R.C.F., Rodrigues, L.B., Santos, L.S. and Veloso, C.M. (2020) Improvement of Texture Properties and Syneresis of Arrowroot (Maranta arundinacea) Starch Gels by Using Hydrocolloids (Guar Gum and Xanthan Gum). Journal of the Science of Food and Agriculture, 100, 3204-3211. https://doi.org/10.1002/jsfa.10356 
[36] Gałkowska, D., Pycia, K., Juszczak, L. and Pająk, P. (2014) Influence of Cassia Gum on Rheological and Textural Properties of Native Potato and Corn Starch. StarchStärke, 66, 1060-1070. https://doi.org/10.1002/star.201400078

[37] Haddad, A.M.L., Ribotta, P., Armada, M. and Goldner, M.C. (2019) Textural, Pasting and Rheological Behavior of Starch-Pectin-Sucrose Gels: Relation with Sensory Perception. Starch-Stärke, 71, Article ID: 1800286.

https://doi.org/10.1002/star.201800286

[38] Teng, L., Chin, N. and Yusof, Y. (2013) Rheological and Textural Studies of Fresh and Freeze-Thawed Native Sago Starch-Sugar Gels. II. Comparisons with Other Starch Sources and Reheating Effects. Food Hydrocolloids, 31, 156-165. https://doi.org/10.1016/j.foodhyd.2012.11.002

[39] Bae, I.Y., Oh, I.K., Jung, D.S. and Lee, H.G. (2019) Influence of Arabic Gum on in Vitro Starch Digestibility and Noodle-Making Quality of Segoami. International Journal of Biological Macromolecules, 125, 668-673.

https://doi.org/10.1016/j.ijbiomac.2018.12.027 